\title{
High pressure interpass rolling of Wire + Arc Additively Manufactured titanium components
}

\author{
Paul A. Colegrove ${ }^{1, a^{*}}$, Filomeno Martina ${ }^{1}$, Matthew J. Roy², Blanka A. Szost ${ }^{3}$, \\ Sofiane Terzi ${ }^{3}$, Stewart W. Williams ${ }^{1}$, Philip J. Withers ${ }^{2}$, David Jarvis ${ }^{3}$ \\ ${ }^{1}$ Cranfield University, Cranfield, Bedfordshire, MK43 OAL UK \\ ${ }^{2}$ The University of Manchester, Oxford Road, Manchester M13 9PL, UK. \\ ${ }^{3}$ ESA-ESTEC, Keplerlaan 1, 2201 AZ Noordwijk, The Netherlands. \\ ap.colegrove@cranfield.ac.uk, bf.martina@cranfield.ac.uk, `matthew.roy@manchester.ac.uk \\ ${ }^{*}$ corresponding author
}

Keywords: additive manufacture, residual stress, distortion.

\begin{abstract}
Wire + Arc Additively Manufactured components contain significant residual stresses that manifest in distortion. Each layer of an additively manufactured wall was rolled with the aim of reducing the residual stress. Neutron diffraction and contour method measurements show that the residual stresses were reduced - particularly at the boundary with the substrate. The process also reduced distortion, and refined the microstructure which may facilitate implementation on aerospace components.
\end{abstract}

\section{Introduction}

Additive manufacture describes a collection of manufacturing processes where components are manufactured by breaking a CAD model down into layers each of which are then deposited using a variety of techniques that are either powder or wire-based. One of those techniques, Wire + Arc Additive Manufacture (WAAM) [1] uses deposition processes based on welding to deposit metal in the form of wire. The process could have a significant and disruptive impact on manufacturing due to: reduced consumption of raw materials; reduced manufacturing costs and lead times; and increased design flexibility.

WAAM is characterised by a number of issues that are slowing its wider implementation. The long, columnar grains in the microstructure of AM components leads to anisotropy [2]. Moreover, Ding et al. [3] describes how steel components are affected by residual stresses and distortion during WAAM. The distortion leads to poor build tolerances, while the residual stress negatively affects part performance. Recently, large residual stresses have been measured in titanium WAAM components by Hoye et al. [4]. Residual stresses have also been reported in parts manufactured by electron beam [5] and laser-based [6,7] additive manufacture processes.

In the related field of welding, one way of counteracting the effect of differential thermal contraction is to induce a compensating plastic strain in the deposited region by mechanical means. Coules et al. [8] describes how high-pressure rolling can also induce the plastic strain required for relaxation of residual stress in welded joints. When carried out after welding, this method comprehensively changed the residual stress distribution, and produced large compressive stresses in the weld. A key advantage of rolling is that it can cause plastic deformation over the entire weld cross-section, rather than just at the surface which is often the case with peening techniques. This counteracts the residual stress caused by welding more effectively, and reduces distortion of the welded component as demonstrated by Wen et al. [9].

In previous work [10] rolling was applied between passes (after cooling to room temperature) of WAAM deposited walls. Two different roller profiles were investigated: the first, called the "profiled" roller, used a grooved profile that matched the top surface of the WAAM deposit. The second, called the "slotted" roller used an additional $10 \mathrm{~mm}$ deep slot to constrain the lateral deformation of the deposited material. Distortion was significantly reduced and in the case of the 
slotted roller it was negligible - being of similar magnitude to the original baseplate. The residual stresses were modified with a significant reduction at the interface between the deposited material and the substrate. Finally microstructural refinement in the deposit was observed due to the combination of plastic work and the subsequent heat treatment from the deposition process. Subsequently, the technique has been applied to titanium WAAM components where the microstructural refinement is even more pronounced converting the deposited anisotropic properties into isotopic ones [11].

In this paper we investigate whether the residual stress modification that was observed in interpass rolled WAAM walls in steel is also observed in titanium and how this compares with a wall in the as deposited state (unrolled).

\section{Methodology}

A Lincoln Electric Invertec V310-T TIG power supply was used to deposit titanium wire onto a $250 \times 60 \times 7 \mathrm{~mm}$ Ti $6 \mathrm{Al} 4 \mathrm{~V}$ substrate. The power supply was attached to a manipulator that was also used for the rolling process which is shown in Fig. 1(a). 40 linear deposits that were $250 \mathrm{~mm}$ long and approximately $5.7 \mathrm{~mm}$ wide and $1.13 \mathrm{~mm}$ high were deposited onto the substrate using the parameters listed in Table 1. The total height of the deposited wall without rolling was $45.2 \mathrm{~mm}$.

Rolling started and ended $35 \mathrm{~mm}$ from the deposit ends and was done at a speed of $3 \mathrm{~mm} \mathrm{~s}^{-1}$ after completing each pass once the material had cooled to room temperature. Cooling of the samples took approximately $2 \mathrm{~min}$. The rolling process used a profiled roller that conformed to the shape of the deposit and is shown in Fig. 1(b). Two loads were applied: $50 \mathrm{kN}$, and $75 \mathrm{kN}$. The three walls were clamped with countersunk bolts along the length of the specimen as shown in Fig. 1(a). The bolts were only released once all the deposition and rolling passes were complete. After completing each sample the maximum out-of-plane distortion was measured with a micrometre by averaging measurements from either end of the sample.

Three cross-sections were extracted from each specimen; they were mounted in resin, ground with 240, 1200 and 2500 grit papers, and then polished with a solution of oxalic acid and waterbased colloidal silica suspension. Etching was performed with a weak hydrofluoric acid solution.

Table 1 Deposition parameters

\begin{tabular}{ll}
\hline Wire feed speed & $1.6\left[\mathrm{~m}_{\mathrm{min}}^{-1}\right]$ \\
\hline Travel speed & $4.5\left[\mathrm{~mm}^{-1}{ }^{-1}\right]$ \\
\hline Peak current & $150[\mathrm{~A}]$ \\
\hline Background current & $70[\mathrm{~A}]$ \\
\hline Average current & $110[\mathrm{~A}]$ \\
\hline Pulse duration & $0.05[\mathrm{~s}]$ \\
\hline Frequency & $10[\mathrm{~Hz}]$ \\
\hline
\end{tabular}




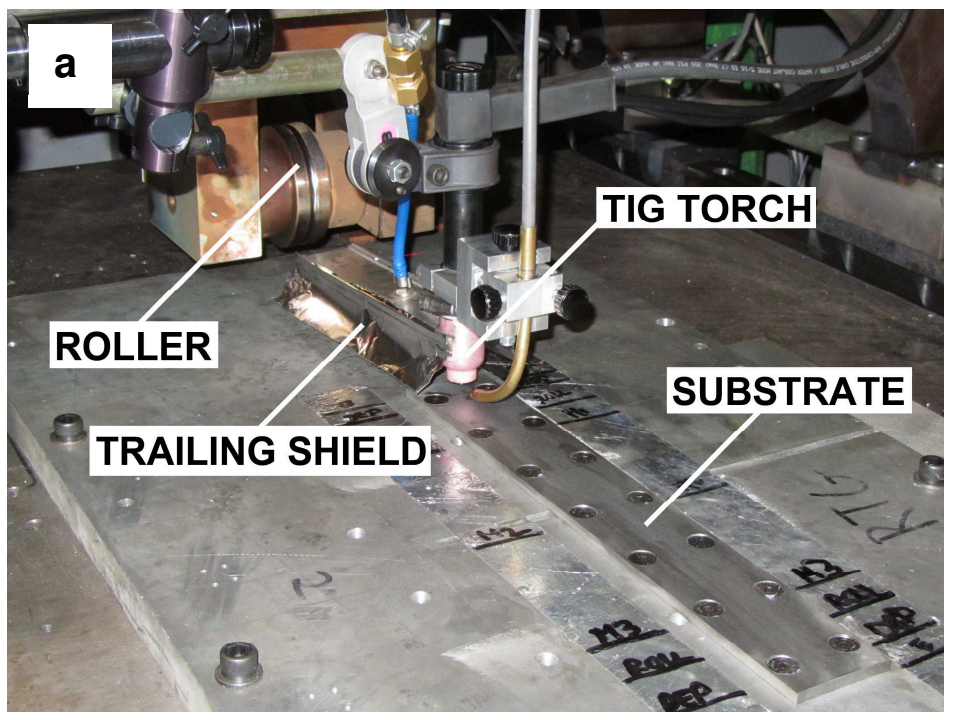

b

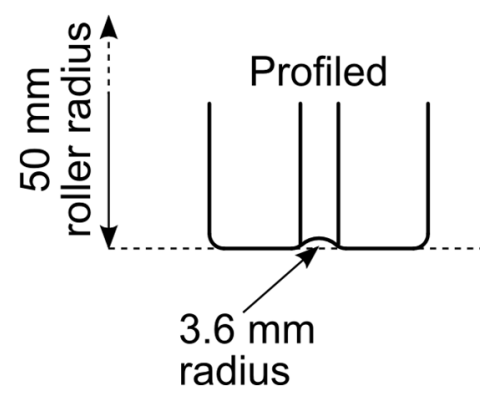

Fig. 1 (a) Photo showing the experimental set-up; and (b) the dimensions of the roller used to roll the titanium deposits.

Residual stress measurements of the reference sample were performed by neutron diffraction with the FRM II instrument at the Heinz Maier-Leibnitz, Garching, Germany, using a wavelength of $1.84 \AA$ and an approximate detector angle of $90^{\circ}$ to measure strain using the $\alpha-\operatorname{Ti}(103)$ crystallographic plane. The scans were done on a sample that was half the original specimen length of $250 \mathrm{~mm}$. Scans started $2 \mathrm{~mm}$ into the baseplate, from its bottom, and finished at the top of the wall, with a spacing of $2 \mathrm{~mm}$ between each point, along the centreline of the wall as shown in Fig. 2. Diffraction peak positions corresponding to lattice strains in the transverse and normal directions were observed using the same setup (with the $X$ axis of the part aligned with the lab. $Z$ axis), while the longitudinal values required three different setups: peak positions of the points within the wall were measured with the part placed horizontally ( $\mathrm{X}$ axis of the part aligned with lab. $\mathrm{X}$ axis), while for the interface wall-baseplate, and for the baseplate itself, two consecutive $45^{\circ}$ rotations of the part around its $\mathrm{X}$ axis were necessary. This was to avoid significant attenuation of the beam due to its passing through the whole width of the baseplate.

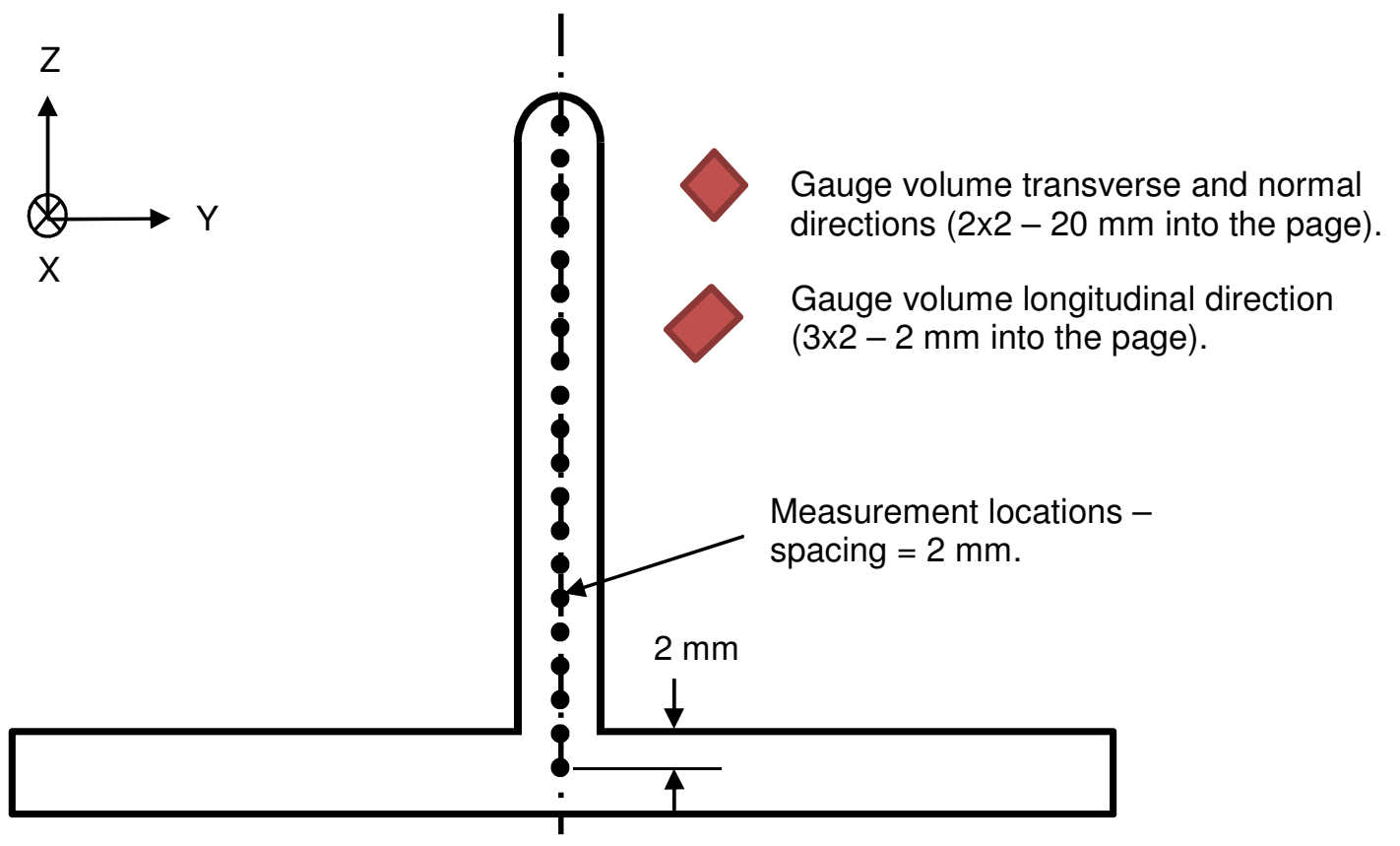

Fig. 2 Diagram showing the location of the nuetron diffraction measurement points, the axes orienatation and the gauge volumes. 
For the transverse and normal directions, a gauge volume of $2 \times 20 \times 2 \mathrm{~mm}^{3}$ was used; while a gauge volume of $3 \times 3 \times 2 \mathrm{~mm}^{3}$ was used for the longitudinal direction (see Fig. 2). For each point, the scan time was at least $15 \mathrm{~min}$. The stress-free lattice spacing, $d_{0}$, was estimated from the average of the lattice parameters, for the three directions measured. Finally, the principal stresses were found using the triaxial form of Hooke's Law:

$$
\sigma_{i i=} \frac{E}{(1+v)(1-2 v)}\left[(1-v) \varepsilon_{i i}+v\left(\varepsilon_{j j}+\varepsilon_{k k}\right)\right]
$$

The residual stress in the sample rolled at $75 \mathrm{kN}$ was measured with the contour method at the University of Manchester. The specimen was cut in half with an EDM operated in skim-cutting mode. The cut commenced at the topmost bead, and traversed through the specimen normal to the baseplate, such that the cutting plane was orthogonal to the longitudinal direction. The two surfaces created as a result of the cut were profiled and digitized with a $30 \mu \mathrm{m}$ resolution employing a $\mu$ Scan nanofocus laser profilometer located at the University of Manchester. The two surfaces were then registered and averaged to provide a single contoured surface, which also eliminated shear artefacts at the edges. A numerical profile based on spline-fitting was interpolated through this surface, with a peak error of $\sim 16 \mu \mathrm{m}$ and a standard deviation of $1.23 \mu \mathrm{m}$ for all measured points. A 3D mesh was defined which conformed to the transverse and longitudinal dimensions of the numerical surface and the physical dimensions of the cut specimen in the longitudinal direction. Boundary conditions were applied at surface nodes to match that of the numerical surface. Appropriate elastic material properties were defined, and the stress state necessary to return the contoured surface to a flat surface obtained using implicit finite element analysis. This technique is documented in greater detail in Johnson [12].

\section{Results and Discussion}

Distortion and Geometry. A plot of the maximum out-of-plane distortion is shown in Fig. 3(a) and illustrates how it reduced with increasing rolling load. The second geometrical effect of rolling was on the height and width of the deposit, which is shown in Fig. 3(b). The negative plastic strain induced by the roller in the build direction reduced the average layer height from around 1.13 to $0.93 \mathrm{~mm}$, however there was a corresponding increase in width in the transverse direction - the average wall width increased from 5.7 to $6.7 \mathrm{~mm}$.

One question that needs to be asked is whether the reduction in distortion is a consequence of the change in stress state induced by the roller, or is it a consequence of the change in the deposit geometry or a combination of the two? In the previous work on rolled steel WAAM [10], an analytical model was developed to predict the distortion of a deposited wall from the dimensions of the deposit. This work demonstrated that the wall geometry produced after rolling did not result in a reduction in distortion - in fact there was a small increase. Therefore the reduction in distortion is most likely to be caused by the plastic strain induced by the roller which modifies the residual stresses.
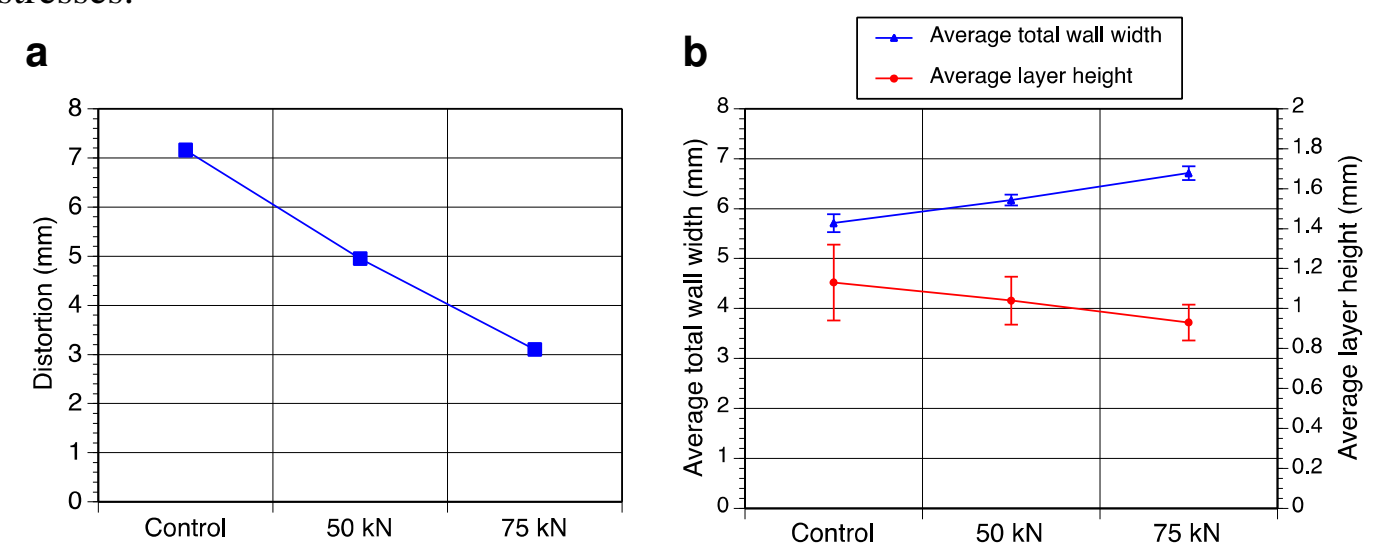

Fig. 3 (a) Maximum out-of-plane distortion of the baseplate and (b) average wall width and height for the three samples. 
Microstructure. All specimens are characterised by a Widmänstatten microstructure, however the prior $\beta$ grains configuration differs substantially between the reference and rolled samples (Fig. 4). The former showed the columnar grains that are typical of AM deposits, which often traverse the whole component (Fig. 4a). The rolled specimens were characterised by a refined microstructure with equiaxed prior $\beta$ grains. When rolled at $50 \mathrm{kN}$ the average grain size was $125 \mu \mathrm{m}$ (Fig. 4b), and when rolled at $75 \mathrm{kN}$ the grain size was $89 \mu \mathrm{m}$ (Fig. 4c). Note however that there was no grain refinement in the top $2 \mathrm{~mm}$ of the rolled specimens. The refinement in the microstructure has been investigated by other authors and is a consequence of reheating the deformed material by the subsequent deposition step. There is some debate over the precise mechanism: whether it is conventional recrystallisation or a consequence of the deformation and rotation of the $\beta$ phase during rolling which increases the number of $\beta$ grains when the material is reheated by the subsequent deposition process.
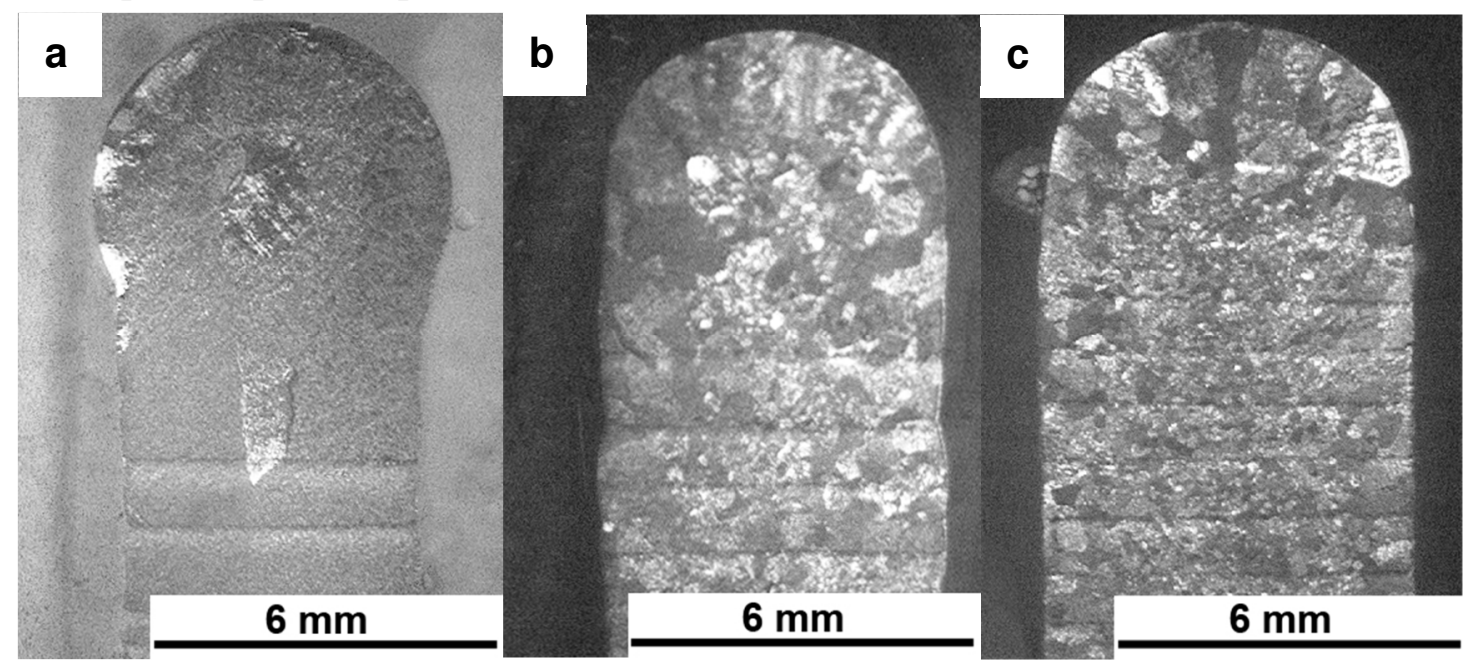

Fig. 4 Optical microscopy images of the top of the deposit from the (a) reference specimen, and the specimens rolled at (b) $50 \mathrm{kN}$ and (c) $75 \mathrm{kN}$.

Residual Stress. The residual stress along the centerline of the reference and rolled (75 $\mathrm{kN})$ samples is shown in Fig. 5(a). Note that since two different techniques were used on two different sample lengths (the neutron diffraction measurements were done on a sample that was half the original length) the results should be compared qualitatively rather than quantitatively. Unsurprisingly, the stress in the longitudinal direction was the greatest for both samples. The peak residual stress in the reference sample occurred at the interface with the baseplate. The peak value of approximately $500 \mathrm{MPa}$ is considerably lower than the yield strength of the deposited material of 810-870 MPa [11]. Similar results in linear walls have been reported in Ding et al. [3] and Colegrove et al. [10] for steel, and Hoye et al. [4] in titanium. As discussed in Ding et al. [3] the deposition process produces a uniform tensile stress in the wall and the stress is similar in magnitude to the yield value of the deposited material while the sample is clamped. All the balancing compressive stresses are accommodated in the baseplate and there is a net bending moment across the section which is provided by the clamps. The relaxation of stresses that occurs during unclamping results in a completely different stress field. The inherent compressive plastic strain in the deposited wall causes the specimen to bend upwards; this distortion significantly reduces the tensile stresses on top of the wall and increases the tensile stresses at the bottom of the baseplate. For equilibrium after unclamping the net bending moment across the section must be equal to zero.

The rolled sample had considerably lower residual stresses which were relatively uniform along the most of the deposit (approx. $150 \mathrm{MPa}$ ) but were highly compressive near the top of the deposit before reversing and becoming slightly tensile. This result is similar to that observed in the rolled steel WAAM parts previously reported [10]. As stated in this paper, even though the roller may effectively eliminate the stresses near the surface, the next deposition run will recreate them. There is a plastic zone associated with the region influenced by the welding process which causes 
development of tensile residual stress. This region is typically much greater than the fusion zone and represents the maximum extent of the residual inherent strain created by the deposition process. There will also be a plastic zone size associated with the rolling process which is seen in the residual stress measurements of Coules et al. [13]. Therefore the final stress state is a competition between the two processes with the final value being determined by the one that influences the greater amount of material. The contour method measurements suggest that the welding process had the greater region of influence, however rolling was able to reduce the magnitude of these stresses, particularly in the region near the baseplate. The tensile stress observed at the very top of the deposit was not reported in the previous work and is likely to be evident due to the greater resolution provided by the contour method results. This stress is possibly of academic rather than practical interest, since this region will be machined off when producing the finished part. In work by Cozzolino [14] tensile stresses were reported in numerical models of welds that were subsequently rolled. As reported in this work, the tensile stresses are a consequence of the coefficient of friction between the roller and the deposit: the deformation under the surface of the roller is greater than at the surface resulting in a tensile stress at the surface and compressive ones underneath. Finally, even though there are tensile stresses along the centerline of the rolled sample (Fig. 5(b)), the stresses along the sides are lower being slightly compressive in same areas, which may be advantageous from a structural integrity perspective.

Finally, the stresses in the transverse and normal directions for both samples are relatively small apart from within the baseplate. This is a consequence of the lack of restraint in either of these directions in the deposited wall.
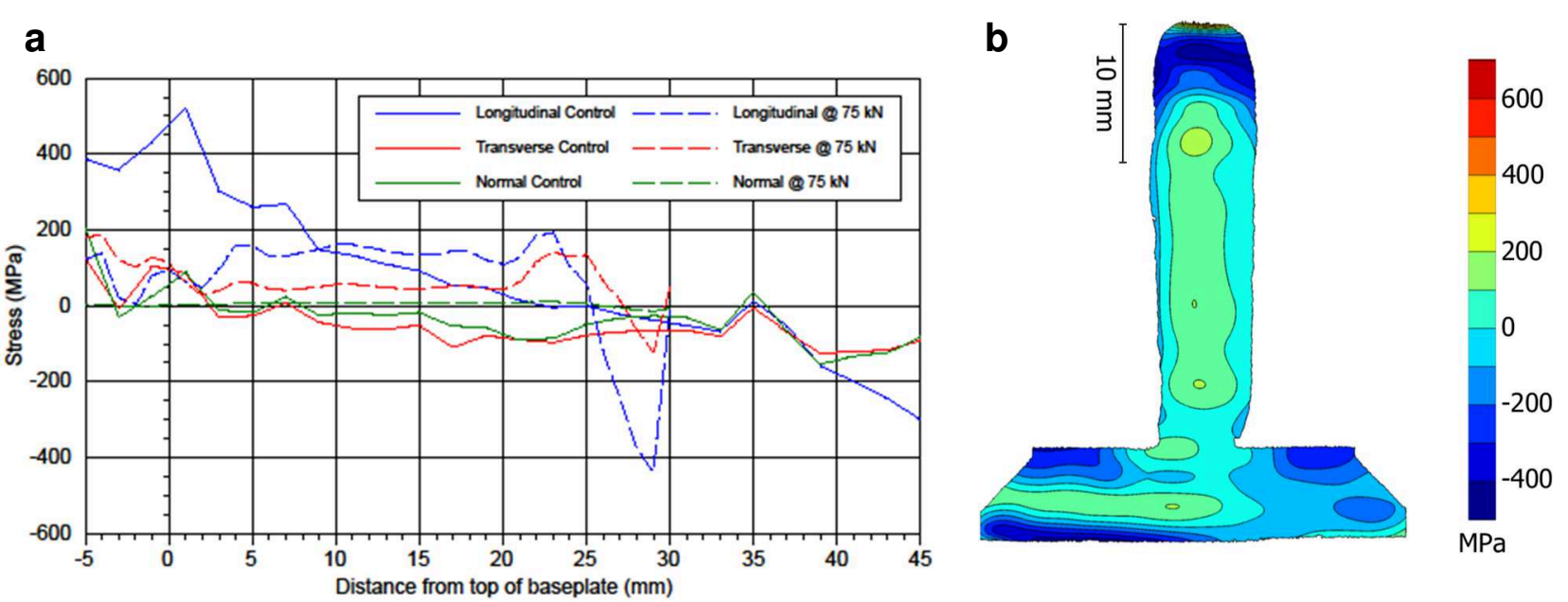

Fig. 5 (a) Residual stresses along the deposit centreline for the reference sample and the sample rolled with a $75 \mathrm{kN}$ load; and (b) contour map of longitidinal residual stress for the rolled sample.

\section{Conclusions}

In this paper we have demonstrated that:

- The distortion of WAAM parts is halved by implementing interpass rolling between the deposited layers;

- The microstructure of the deposited walls is modified significantly: in the reference sample the prior $\beta$ traverse the whole component while in the rolled samples they are equiaxed.

- Interpass rolling has significantly modified the residual stresses, particularly at the interface between the deposit and baseplate where the peak tensile stress was reduced significantly. In addition, the rolling process induced a significant compressive stress near the top of the deposit which reversed and became slightly tensile at the surface. 


\section{Acknowledgements}

The authors wish to acknowledge financial support from EADS Innovation Works and the AMAZE Project, which is co-funded by the European Commission in the 7th Framework Programme (contract FP7-2012-NMP-ICT-FoF-313781), by the European Space Agency and by the individual partner organisations. In addition, the authors would like to thank Supriyo Ganguly, John Francis, Philipp Frankel, Jon Meyer, Andrew Henstridge, Flemming Nielsen, Brian Brooks and Michael Hofmann for the assistance that they provided in undertaking this work.

\section{References}

[1] F. Martina, J. Mehnen, S.W. Williams, P. Colegrove, F. Wang, Investigation of the benefits of plasma deposition for the additive layer manufacture of Ti-6Al-4V, J. Mater. Process. Technol. 212 (2012) 1377-1386.

[2] F. Wang, S. Williams, P. Colegrove, A.A. Antonysamy, Microstructure and mechanical properties of wire and arc additive manufactured Ti-6Al-4V, Metall Mat Trans A Phys Metall Mat Sci. 44 (2013) 968-977.

[3] J. Ding, P. Colegrove, J. Mehnen, S. Ganguly, P.M.S. Almeida, F. Wang, S. Williams, Thermomechanical analysis of Wire and Arc Additive Layer Manufacturing process on large multilayer parts, Computational Materials Science. 50 (2011) 3315-3322.

[4] N. Hoye, H. Li, D. Cuiuri, A. Paradowska, Measurement of Residual Stresses in Titanium Aerospace Components Formed via Additive Manufacturing, Materials Science Forum. 777 (2014) 124-129.

[5] P. Edwards, A. O'Conner, M. Ramulu, Electron beam additive manufacturing of titanium components: Properties and performance, J. Manuf. Sci. Eng. Trans. ASME. 135 (2013).

[6] Y.B. Lai, W.J. Liu, J.B. Zhao, Y.H. Zhao, F.Y. Wang, W.C. Han, Experimental study on residual stress in titanium alloy laser additive manufacturing, Applied Mechanics and Materials. 431 (2013) 20-26.

[7] S. Marimuthu, D. Clark, J. Allen, A.M. Kamara, P. Mativenga, L. Li, R. Scudamore, Finite element modelling of substrate thermal distortion in direct laser additive manufacture of an aero-engine component, Proc. Inst. Mech. Eng. Part C. 227 (2013) 1987-1999.

[8] H.E. Coules, P. Colegrove, L.D. Cozzolino, S.W. Wen, J.F. Kelleher, High pressure rolling of low carbon steel weld seams: Part 2 - Roller geometry and residual stress, Science and Technology of Welding and Joining. 18 (2012) 84-90.

[9] S.W. Wen, P.A. Colegrove, S.W. Williams, S.A. Morgan, A. Wescott, M. Poad, Rolling to control residual stress and distortion in friction stir welds, Science and Technology of Welding and Joining. 15 (2010) 440-447.

[10] P.A. Colegrove, H.E. Coules, J. Fairman, F. Martina, T. Kashoob, H. Mamash, L.D. Cozzolino, Microstructure and residual stress improvement in wire and arc additively manufactured parts through high-pressure rolling, J. Mater. Process. Technol. 213 (2013) 17821791.

[11] F. Martina, S.W. Williams, P.A. Colegrove, Improved microstructure and increased mechanical properties of additive manufacture produced Ti-6Al-4V by inter pass cold rolling. 24th International Freeform Fabrication Symposium, Austin, Texas, USA, August 12-14. (2013).

[12] G. Johnson, Residual stress measurements using the contour method, Ph. D. Dissertation, University of Manchester, School of Materials. (2008).

[13] H.E. Coules, P. Colegrove, L.D. Cozzolino, S.W. Wen, S. Ganguly, T. Pirling, Effect of high pressure rolling on weld-induced residual stresses, Science and Technology of Welding and Joining. 17 (2012) 394-401.

[14] L.D. Cozzolino, Finite element analysis of localised rolling to reduce residual stress and distortion, Ph. D. Dissertation, Cranfield University, School of Applied Science. (2013). 